\title{
APRECIAÇÃO ERGONÔMICA DA CABINA DE TRATORES AGRÍCOLAS - VISIBILIDADE
}

\section{APPRECIATION ERGONOMICS OF CABIN OF THE AGRICULTURAL TRACTORS - VISIBILITY}

\author{
Mauro Tavares Menegas \\ Engenheiro Mecânico \\ Mestre Engenheiro de Produção. \\ Departamento de Engenharia, Arquitetura e Ciências Agrárias. \\ UNISC - Universidade de Santa Cruz do Sul. \\ Santa Cruz do Sul, RS - CEP:96815-900 - Fone:(051)3717-7382 \\ e-mail: mmenegas@,bol.com.br
}

\author{
Dr Arno Udo Dallmeyer \\ Engenheiro Agrônomo \\ UFSM - Centro de Tecnologia \\ Programa de Pós-Graduação em Engenharia de Produção (PPGEP) \\ Campus-Camobi, Santa Maria, RS - CEP:97105-900 \\ Fone: (055)220-8598
}

\author{
Dr. Fernando Scholosser \\ Engenheiro Agrônomo \\ UFSM - Centro de Ciências Rurais
}

Departamento de Engenharia Rural, Núcleo de Ensaios de Máquinas Agrícolas (NEMA)

Campus-Camobi, Santa Maria, RS - CEP:97105-900

Fone: (055)220-8598 


\title{
RESUMO
}

Este trabalho apresenta um estudo da perda visual do operador de um trator agrícola durante o seu trabalho no campo comparando-se um trator cabinado e não-cabinado. A metodologia utilizada foi definida pela Norma ISO 5721/81: Agricultural tractors - Operator's field of vision. Foram determinados os campos visuais $\mathrm{A}, \mathrm{B}$ e $\mathrm{C}$ a partir da posição dos olhos do operador nos planos $0^{\circ},+30^{\circ}$ e $-20^{\circ}$. Nesses planos foram calculados os efeitos-máscara causados por cada um dos obstáculos. No plano ao nível do solo determinou-se a perda visual pela projeção das sombras em cada campo visual. Os resultados obtidos demonstraram que a utilização da cabina diminui o campo de visão do operador nos campos $\mathrm{B}$ e $\mathrm{C}$ em todos os planos $0^{\circ},+30^{\circ}$ e $-20^{\circ}$ e que no campo A se mantêm os mesmos valores em cada plano. Ao nível do solo, a perda de visibilidade é muito maior no campo visual B e mínima em A e C.

Palavras-chave: visibilidade, campos visuais, perda visual.

\begin{abstract}
This work to present a study of the visual loss of the operator of agricultural tractor during its work in the field being compared a tractor with cabin and without cabin. The used methodology was going defined by Standard ISO 5721/81: Agricultural tractors - Operator's field of vision. They were going determined the visual fields $\mathrm{A}, \mathrm{B}$ and $\mathrm{C}$ starting from the position of the eyes of the operator in the plans $0^{\circ},+30^{\circ}$ and $-20^{\circ}$. In that plans they were going calculates the effect-mask caused by each one of the obstacles. In the plan at the level of the soil. the visual loss was determined by the projection of the shade in each visual field. The obtained results demonstrated that the use of the cabin decreases the field of vision of the operator in the fields $\mathrm{B}$ and $\mathrm{C}$ in all the plans $0^{\circ},+30^{\circ}$ and $-20^{\circ}$ and that in the field $\mathrm{A}$ they stay the same values in each plan. At the level of the soil, the visibility loss is very larger in the visual field $\mathrm{B}$ and minimum in $\mathrm{A}$ and $\mathrm{C}$.
\end{abstract}

Key-words: visibility, visual fields, visual loss.

\section{INTRODUÇÃO}

O surgimento do trator agrícola no início do século teve como principal objetivo a substituição da mão-de-obra dos animais nos trabalhos agrícolas. O que impulsionou a construção desses primitivos tratores foram as duas deficiências básicas dos animais 
domésticos como fonte de potência para fins agrícolas: a baixa capacidade em desenvolver esforço de tração e a natural inadequação para fornecer potência em movimento de rotação.

Com o passar do tempo, o projeto do trator foi sendo aperfeiçoado para que este pudesse exercer muitas outras tarefas além de tracionar máquinas de preparo do solo e acionar, através de correias e polias, trilhadoras de cereais, por exemplo. Esse desenvolvimento em seu projeto sempre visou a sua melhor adaptação ao trabalho, isto é, sempre enfocando a relação trabalho-máquina deixando de fora uma parte de igual importância: o homem. Somente com o surgimento da ergonomia após a II Guerra Mundial é que se relacionou o homem ao trator e os projetos passaram a contar com dois novos fatores de preocupação para os projetistas: a segurança e o bem-estar do operador.

A partir dessa nova relação homem-máquina muitos trabalhos antropométricos foram realizados com o intuito de se determinar medidas padrões para o homem e, de posse desses dados, os tratores passaram a ser projetados de forma a se adaptarem ao homem e não ao contrário como vinha acontecendo. Assim sendo, estudos a respeito da fisiologia do homem, dos seus sentidos, etc. tornaram-se também necessários e muitos foram realizados a fim de se obter uma melhor relação homem-máquina e, conseqüentemente, melhorar a produção da máquina no desempenho de suas funções.

Este trabalho tem como objetivo determinar a perda visual do operador de trator agrícola durante o seu trabalho no campo comparando-se um trator com cabina com um trator sem cabina. Para isto determinou-se os campos visuais $\mathrm{A}, \mathrm{B}$ e $\mathrm{C}$ a partir da posição dos olhos do operador nos planos $0^{\circ}$ (horizontal), $+30^{\circ}$ (acima do plano horizontal) e $-20^{\circ}$ (abaixo do plano horizontal). Dentro desses campos todos os obstáculos foram localizados utilizando-se uma fonte de luz (laser). Como neste caso isso representaria uma visão uniocular, tornou-se necessário o cálculo do efeito-máscara causado por cada um desses obstáculos a fim de representar-se a perda real de visibilidade para uma visão binocular que é a visão normal do ser humano. No plano horizontal ao nível do solo determinou-se a perda visual pela projeção da sombra do trator com cabina e sem cabina utilizando-se uma fonte de luz (lâmpada). Os resultados obtidos demonstraram que a utilização da cabina diminui o campo de visão do operador nos campos de visão laterais $\mathrm{B}$ e $\mathrm{C}$ em todos os planos $\left(0^{\circ},+30^{\circ}\right.$ e $\left.-20^{\circ}\right)$ e que no campo de visão frontal A se mantêm os mesmos valores em cada plano. Ao nível do solo, a utilização da cabina faz com que a perda de visibilidade seja muito maior no campo visual lateral B e mínima no campo visual frontal A e no campo visual lateral C.

Com esses resultados, constatou-se que o campo visual B é o mais prejudicado com o uso de cabina no trator agrícola e que, portanto, em seu projeto deve-se levar em conta os obstáculos individualmente, repensando-se na sua largura, posição e forma a fim de se diminuir o efeito-máscara causado pelo mesmo o que aumentaria o campo visual do operador e melhoraria sua condição de trabalho, aumentando sua produtividade.

\section{Procedimentos.}

Para a realização das avaliações propostas neste trabalho foi utilizado um trator Massey-Ferguson 5290 sem cabina (figura 1) cujas características da plataforma do operador são: plataforma integrada com o pára-lamas, montada sobre coxins de borracha; toldo e EPCC - Estrutura de Proteção Contra Capotagem; assento com regulagens na suspensão e posição horizontal. Na segunda parte do experimento, a cabina utilizada no trator (figura 2), específica para os tratores Massey-Ferguson da série 5000, é do tipo pressurizada, com ar condicionado e calefação, montada sobre coxins de borracha e tendo uma estrutura de proteção contra capotagem (EPCC) com 4 pontos de apoio tendo como características: estrutura metálica; 
vidros temperados; amortecedores na porta e janela traseira; isolamento termo-acústico no teto; ventilação forçada; ar condicionado (opcional); climatizador (ar úmido) (opcional); forração interna (opcional).

De acordo com a Norma ISO 5721/81 o trator sob teste estava descarregado e sem lastro e os pneus estavam com pressão recomendada pelo fabricante para uso em estrada. As bitolas utilizadas no trator durante o experimento foram: $1390 \mathrm{~mm}$ (dianteira) e $1525 \mathrm{~mm}$ (traseira).

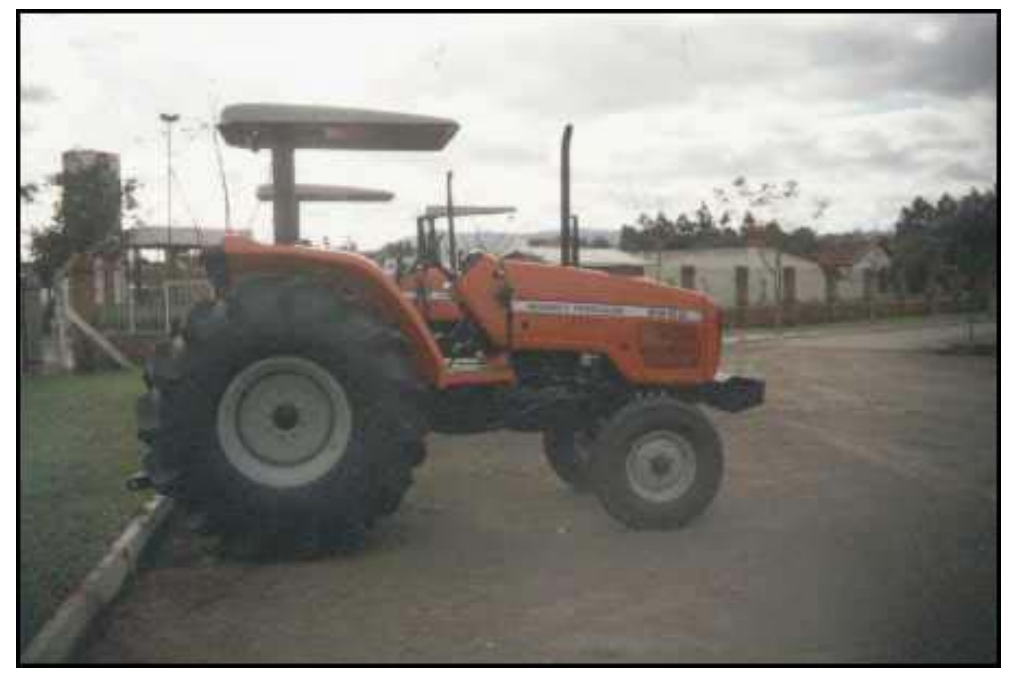

FIGURA 1 - Trator Massey-Ferguson 5290 sem cabina.

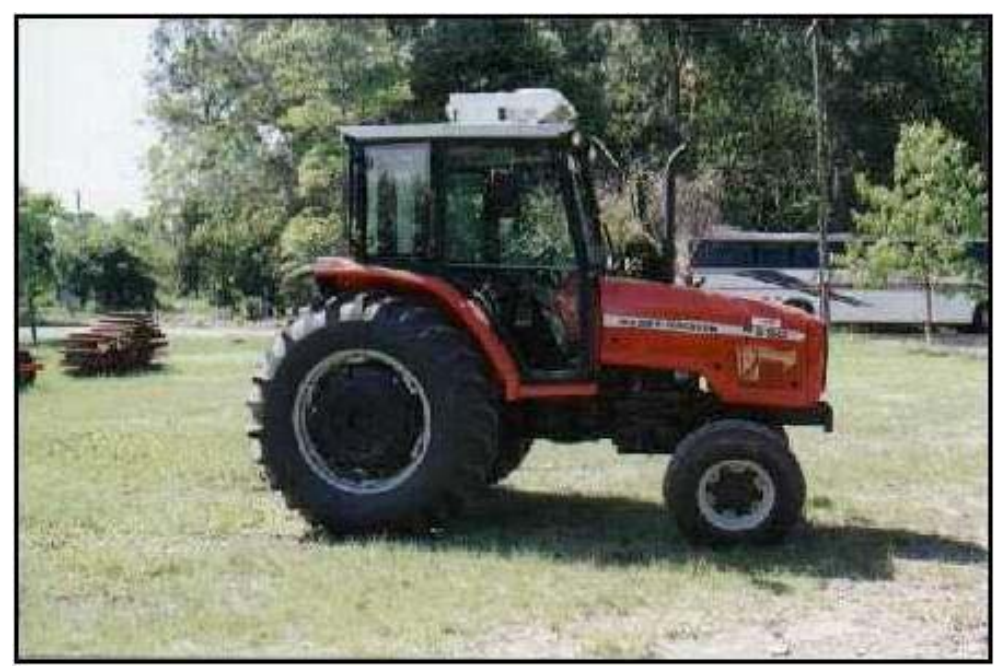

FIGURA 2 - Trator Massey-Ferguson 5290 com cabina.

\subsection{Avaliação da Visibilidade.}


O piso da área de teste foi dividido em quadrados de $1 \mathrm{~m}$ x $1 \mathrm{~m}$ formando um sistema de referência $\mathrm{XY}$ cuja origem seria o centro dos semicírculos de visão dianteiro e traseiro. $\mathrm{O}$ trator foi posicionado de modo a fazer coincidir verticalmente esse centro com o Ponto de Referência (PR) do banco do operador. A determinação da altura da posição dos olhos do operador em relação ao assoalho da cabina foi obtida com a colocação de um peso de $75 \mathrm{~kg}$ sobre o banco para simular a deflexão do mesmo pelo peso do operador durante o seu trabalho. Em seguida, medindo-se a distância vertical do assoalho da cabina até o PR do assento deflexionado e somando-se $760 \mathrm{~mm}$ obteve-se a altura da posição dos olhos em relação ao assoalho da cabina. Com a medida da distância horizontal entre a parede traseira da cabina e o encosto do banco somada à $150 \mathrm{~mm}$ obteve-se a localização da posição dos olhos do operador. Esses procedimentos foram determinados segundo a Norma ISO 5721/1981 (figura 3).

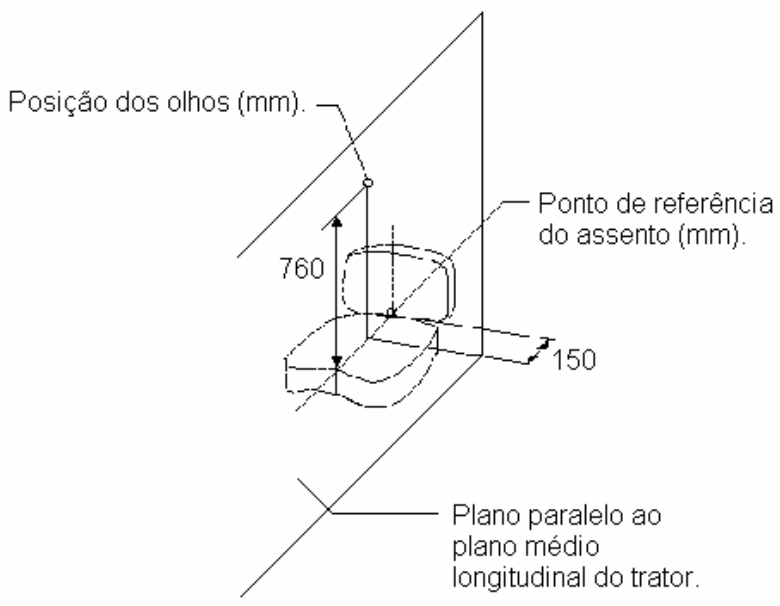

FIGURA 3 - Determinação da posição dos olhos em relação ao assento no posto de comando do trator.

FONTE: ISO 5721, 1981, p. 492.

Com isso pode-se remover o banco do trator e montar o tripé com o teodolito e o laser, posicionando-os na posição dos olhos encontrada e, a partir daí, demarcar os campos visuais $\mathrm{A}, \mathrm{B}$ e $\mathrm{C}$ e, ainda, os planos de visão $0^{\circ},+30^{\circ}$ e $-20^{\circ}$. Em cada plano de visão foram determinados os ângulos que posicionam os obstáculos dentro de cada campo visual. Para a determinação da sombra projetada no solo da área de teste foi feita a substituição do laser e do teodolito por uma lâmpada de 150 watts de potência e o escurecimento do ambiente. Em seguida a sombra foi demarcada e tendo-se a área de teste como um sistema cartesiano, cuja origem é o centro dos semicírculos de visão, alguns pontos sobre a sua linha de contorno foram determinados obtendo-se, assim, suas coordenadas. Utilizando-se o software AUTOCAD R14 pode-se desenhar a sombra obtida e a projeção do próprio trator e ainda calcular suas áreas, bem como desenhar os campos visuais demonstrando e calculando as áreas obscuras causadas pelos obstáculos. Como foi utilizada apenas uma fonte de luz, o efeito-máscara foi calculado matematicamente segundo a Norma ISO 5721/81, bem como os planos $0^{\circ},+30^{\circ}$ e $-20^{\circ}$, conforme a figura 4 . 


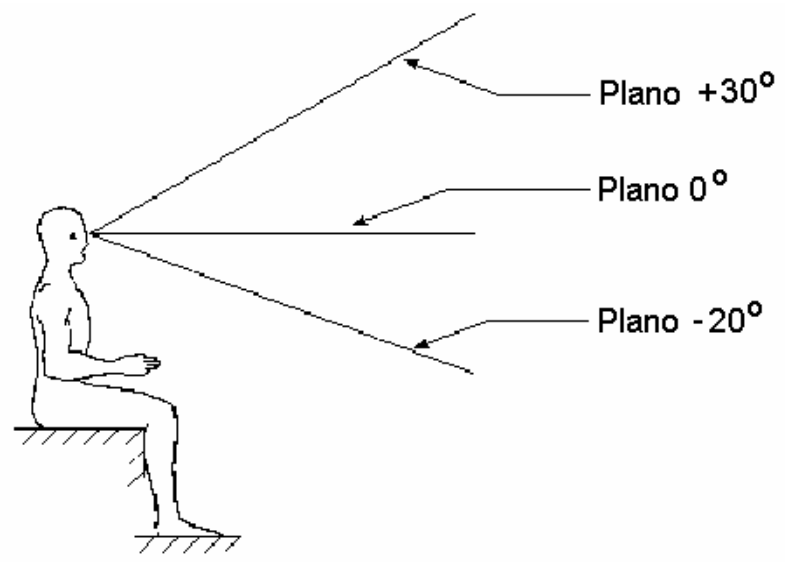

FIGURA 4 - Planos de visão $0^{\circ},+30^{\circ}$ e $-20^{\circ}$.

Os campos visuais A, B e C foram marcados nas paredes da área de teste com o laser no plano horizontal a partir da posição $0^{\circ}$ situada à frente no plano longitudinal do trator e rebatidos para os outros planos. Os ângulos marcados foram:

- Campo Visual A: $+25^{\circ}$ e $-25^{\circ}$.

- Campo Visual B: $+85^{\circ}$ e $-85^{\circ}$.

- Campo Visual C: $+150^{\circ}$ e $-150^{\circ}$.

A figura 5 apresenta a marcação dos campos visuais.

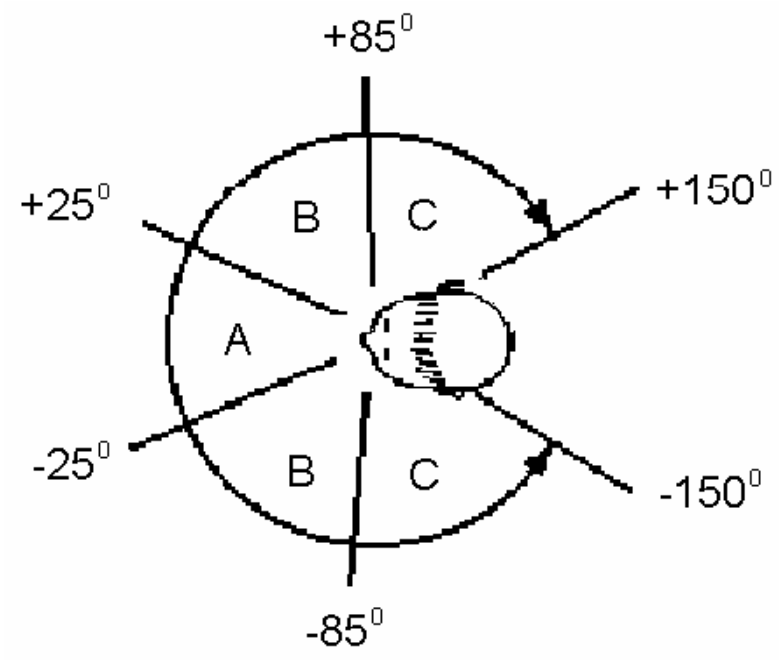

FIGURA 5 -Campos Visuais A, B e C.

FONTE: MENEZES, João F.; MAZIERO, José V.; YAMASHITA, Rosa Y. at al., 1985 , p. 5. 


\section{Resultados.}

\subsection{Sombra projetada no solo da área de teste.}

Para a obtenção da projeção da sombra no solo da área de teste foi determinado um raio de $10 \mathrm{~m}$ a partir do centro do círculo de visão. Este círculo foi dividido em três campos visuais $\mathrm{A}, \mathrm{B}$ e $\mathrm{C}$ e a representação das sombras obtidas dentro destes campos de visão para o trator com cabina e sem cabina está demonstrada nas figuras 6 e 7 .

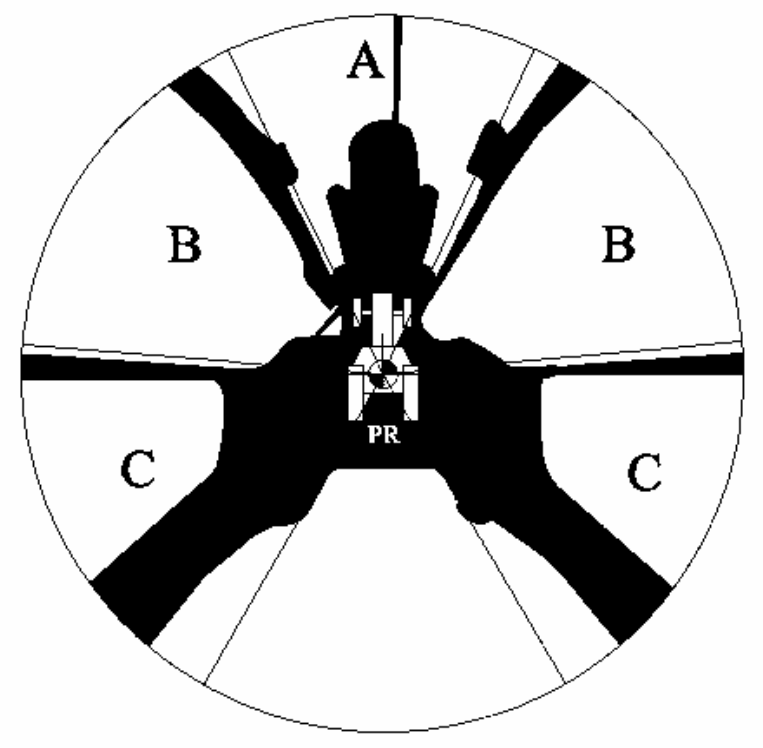

FIGURA 6 - Projeção da sombra do trator com cabina dentro do círculo de visão nos planos $\mathrm{A}, \mathrm{B}$ e C.

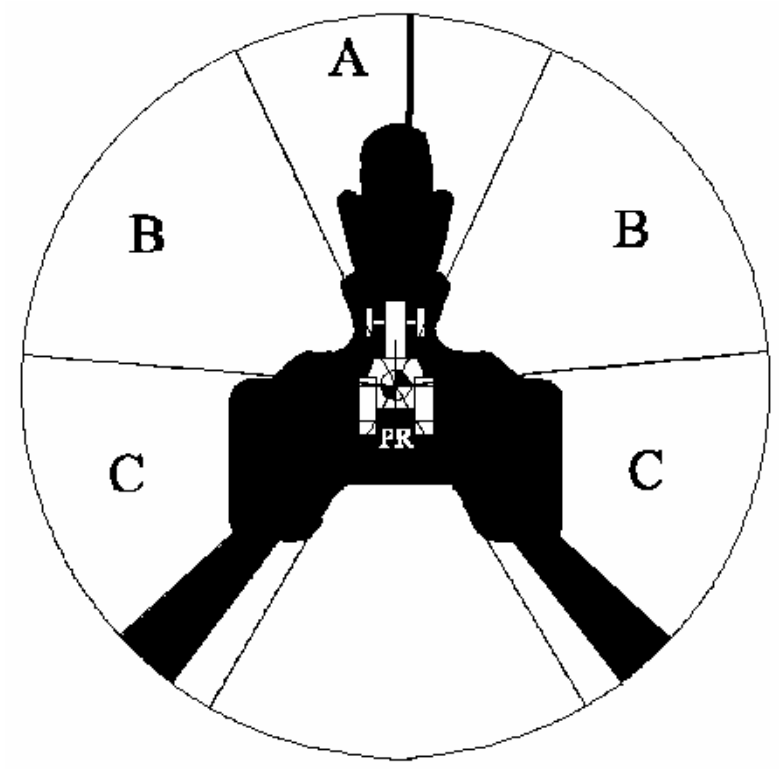

FIGURA 7 - Projeção da sombra do trator sem cabina dentro do círculo de visão nos planos A, B e C. 
Ao se comparar as duas figuras, observa-se que a utilização da cabina gera no campo visual A uma pequena parcela da sombra dos espelhos e faroletes. Já no campo visual B a sombra gerada é das colunas dianteiras que sustentam o pára-brisa. No campo visual $\mathrm{C}$ a sombra gerada pela cabina é das colunas laterais e das colunas traseiras.

A tabela 1 apresenta as áreas dos campos visuais $\mathrm{A}, \mathrm{B}$ e $\mathrm{C}\left(\mathrm{A}_{\mathrm{cV}}\right)$ e as áreas obscuras em cada campo visual $\left(A_{t o}\right)$ projetadas no piso da área de teste. A relação entre as áreas $A_{\text {to }} /$ $\mathrm{A}_{\mathrm{cv}}$ é apresentada na tabela 2 .

TABELA 1 - Áreas dos campos visuais e áreas obscuras em cada campo.

\section{CAMPO VISUAL A CAMPO VISUAL B CAMPO VISUAL C}

\begin{tabular}{lcccrcc} 
TRATOR & $\mathbf{A}_{\mathbf{c v}}$ & $\mathbf{A}_{\text {to }}$ & $\mathbf{A}_{\mathbf{c v}}$ & \multicolumn{1}{c}{$\mathbf{A}_{\text {to }}$} & $\mathbf{A}_{\mathbf{c v}}$ & $\mathbf{A}_{\text {to }}$ \\
C/CABINA & 43,63 & 14,39 & 104,72 & 16,02 & 113,45 & 50,90 \\
S/CABINA & 43,63 & 12,05 & 104,72 & 5,65 & 113,45 & 33,45
\end{tabular}

TABELA 2 - Relação entre a área do campo visual e a área obscura dentro do campo

\begin{tabular}{cccc} 
& \multicolumn{4}{c}{$\mathbf{A}_{\text {to }} / \mathbf{A}_{\mathbf{c v}}$} \\
TRATOR & CAMPO VISUAL A & CAMPO VISUAL B & CAMPO VISUAL C \\
C/CABINA & 0,3298 & 0,1530 & 0,4487 \\
S/CABINA & 0,2762 & 0,0549 & 0,2948
\end{tabular}

Os valores obtidos indicam que tanto o trator com cabina como o trator sem cabina apresentam a pior condição de visibilidade no campo visual $C$, porque é neste campo que ocorre a maior relação $A_{t o} / A_{c v}$, o que pode ser melhor observado através do gráfico 1.

Os valores ideais para a relação $A_{t o} / A_{c v}$ são os mais próximos de zero pois isso indicaria que a sombra projetada seria pequena em relação ao campo visual. Isso acontece no campo visual B nas duas situações (trator com cabina e trator sem cabina), pois os valores encontrados para a relação são os menores dos três campos visuais. 
GRÁFICO 1 - Relação entre a área total obscura em cada campo visual e a área do próprio campo visual.

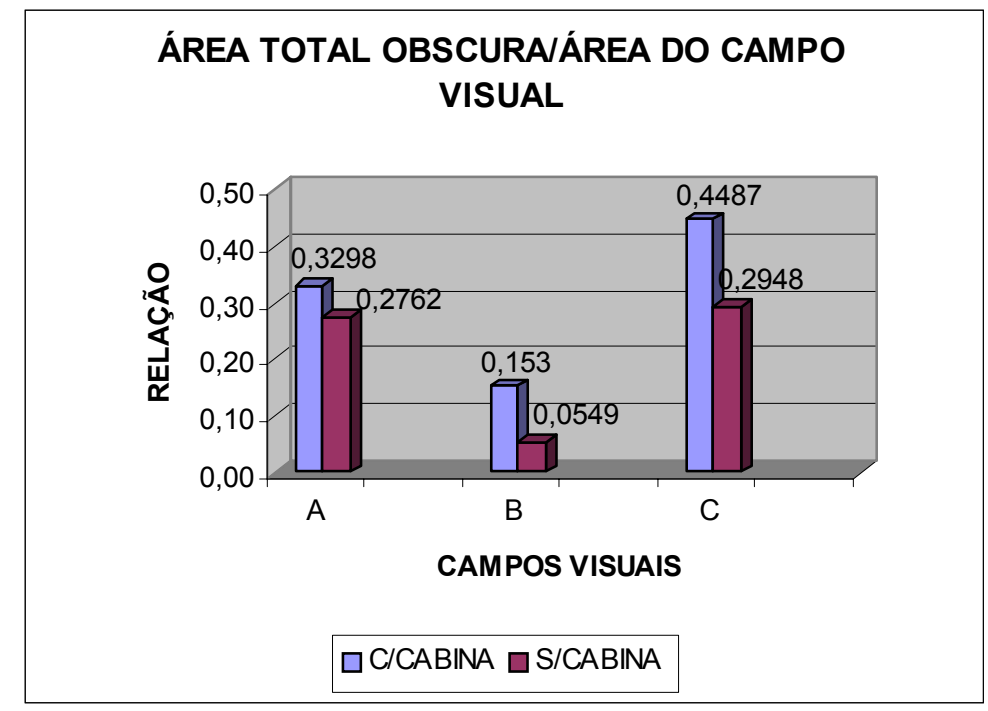

Logo, se observa que o uso da cabina afeta mais o campo de visão do operador na área ao seu redor em que ele vai se concentrar um pouco mais durante o seu trabalho que é o campo visual C. Isso ocorre neste campo visual devido à utilização dos implementos agrícolas em suas tarefas no campo que, segundo IIDA (1997) conforme o tipo de tarefa em execução, o tratorista irá gastar de 40 a $60 \%$ do seu tempo olhando para trás, envolvendo um grande número de movimentos rotacionais da cabeça, para à frente e para trás, que chegam a até 15 ou 20 rotações por minuto (que corresponde a 3 ou 4 segundos por rotação).

\subsection{Efeito-máscara.}

Efeito-máscara: são cordas dos setores de um semicírculo de visão as quais não podem ser vistas a partir da posição dos olhos devido aos componentes estruturais do trator.

Com os resultados obtidos com o cálculo do efeito-máscara construiu-se um gráfico comparativo entre os três planos de visão $0^{\circ},+30^{\circ}$ e $-20^{\circ}$ para cada um dos campos visuais A, B e C.

No campo visual A verificou-se que no trator não houve variação na percentagem de área obscura nos três planos de visão do operador, o que é representado no gráfico 2. O único obstáculo que causou uma perda de visão foi o cano-de-descarga, tanto no caso do trator estar com a cabina, como no caso de estar sem a cabina. 
GRÁFICO 2 - Comparativo entre os três planos de visão $0^{\circ},+30^{\circ}$ e $-20^{\circ}$ no campo visual A.

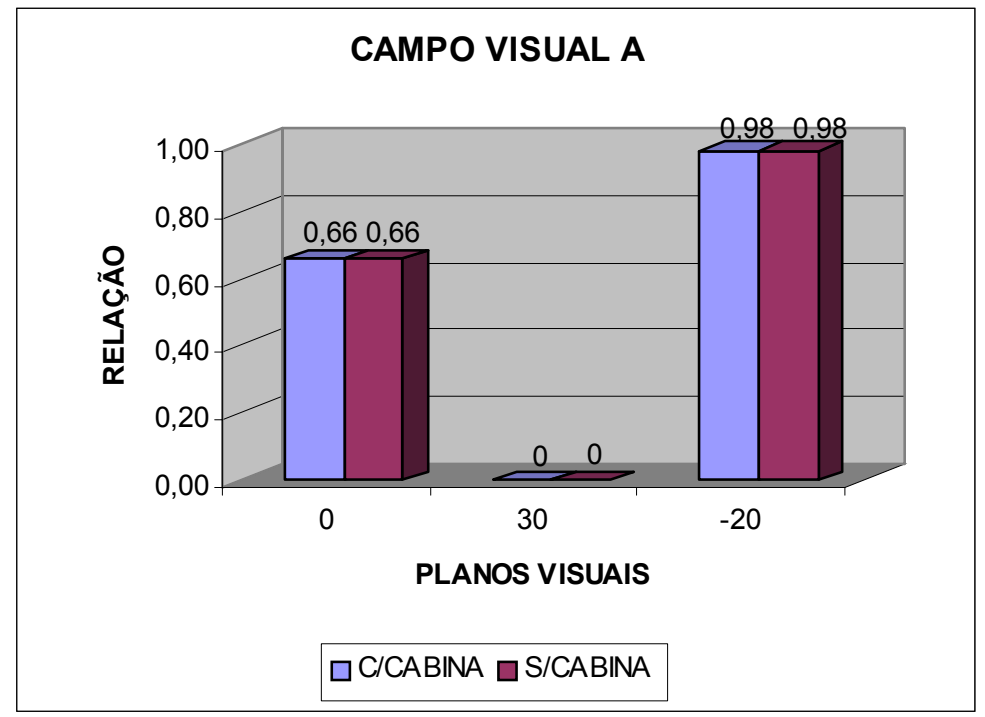

No gráfico 3 é representado o comparativo no campo visual B onde observa-se que a variação na percentagem de perda de visão foi maior pois foi causada pelos cantos do párabrisa, pelos espelhos e pelos faroletes, todos eles elementos estruturais da cabina. De um plano para o outro esses valores tiveram uma variação devido à inclinação dada ao pára-brisa. Neste campo a melhor visibilidade está localizada em ângulos mais abertos devido à grande área de transparência utilizada nas laterais do trator.

GRÁFICO 3 - Comparativo entre os três planos de visão $0^{\circ},+30^{\circ}$ e $-20^{\circ}$ no campo visual B.

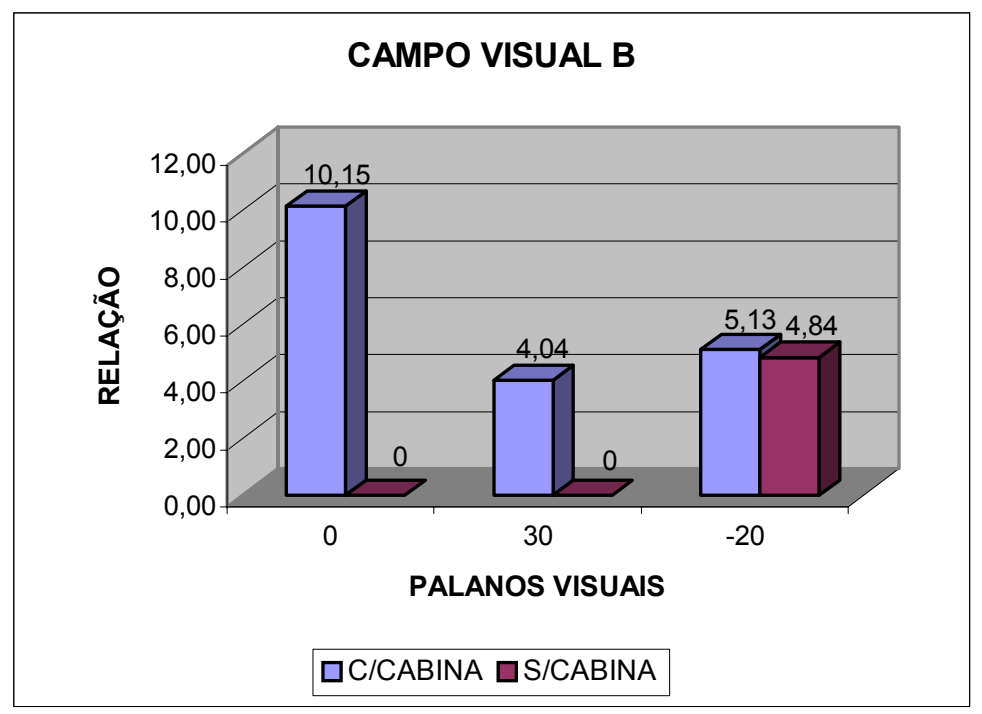


O campo visual $\mathrm{C}$, representado no gráfico 4, manteve os mesmos seis obstáculos causando perda de visão em todos os planos no caso do trator com cabina e os mesmos dois obstáculos no caso do trator sem cabina.

GRÁFICO 4 - Comparativo entre os três planos de visão $0^{\circ},+30^{\circ}$ e $-20^{\circ}$ no campo visual C.

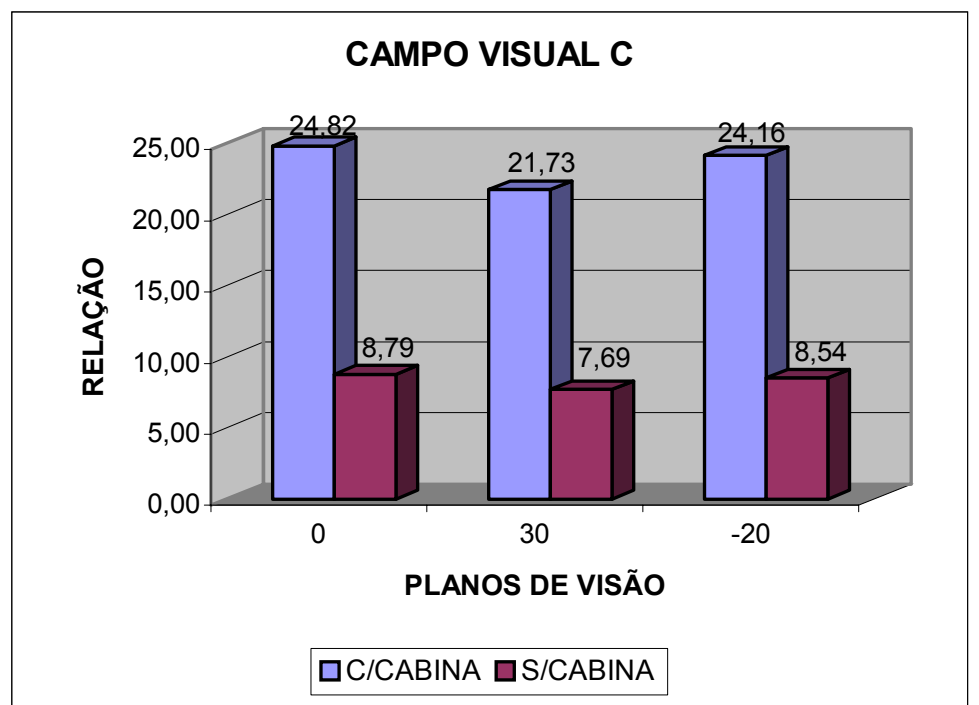

\section{Conclusão.}

O trator estudado apresentou uma grande variação nos resultados obtidos nos testes de visibilidade no campo visual do operador para as duas situações em que, primeiro, estava com a cabina montada em sua estrutura e, segundo, quando estava sem a cabina. Quando a análise foi feita nos planos $0^{\circ},+30^{\circ}$ e $-20^{\circ}$ as maiores variações se apresentaram no Campo Visual B, mas quando a análise é feita no plano ao nível do solo é no Campo Visual C que se encontra a maior variação. Essa distorção nos resultados se deve ao fato de que, no primeiro caso, foi levada em conta a visão binocular e, portanto, apenas os obstáculos que causaram o efeitomáscara foram considerados e, no segundo, a área obscura foi causada por todos os obstáculos por ter sido utilizado um ponto de luz para determiná-la e, assim, representou uma visão uniocular que não é a visão normal do operador.

Portanto, como a distância entre o ponto de referência e o obstáculo e a largura do mesmo determinam a existência ou não do efeito-máscara, como é demonstrado na fórmula para o seu cálculo (ISO 5721/81), isto implica que o número de obstáculos, ao contrário do que possa ser pensado, não determina uma maior ou menor área obscura nos campos visuais, mas sim a posição e o tamanho dos mesmos. Logo, um trator com cabina poderá vir a ter uma visibilidade muito próxima a que possui quando está sem cabina bastando, para isso, que o projeto da mesma se preocupe com a posição e a largura das partes que compõem sua estrutura bem como a colocação de partes transparentes nos locais adequados.

Como não existe um parâmetro que determine uma melhor ou pior visibilidade de uma cabina, a análise teve que ser feita relacionando-se um trator com cabina e o mesmo trator sem cabina. 
Para o cálculo do efeito-máscara é necessário que a linha que une os olhos do operador esteja perpendicular ao eixo que determina a distância entre a sua posição e o obstáculo. No trabalho de campo isso até acontece nos campos visuais A e B, mas no campo visual $\mathrm{C}$ se torna mais difícil a medida que aumenta o ângulo de abertura em direção ao seu valor limite de $150^{\circ}$. 


\section{REFERÊNCIAS}

AGCO DO Brasil. Catálogo Trator MF 5290/2. junho 1998. . Catálogo Cabina MF linha 5000.

ALMEIDA, Márcio. Vibrações Mecânicas para Engenheiros, São Paulo-SP : ed. Edgard Blücher, 1987, 400 p.

BARGER, E. L. at all. Tratores e seus Motores, São Paulo-SP : ed. Edgard Blücher, 1966, $398 \mathrm{p}$.

BORGMAN, D.E., HAINLINE, E., LONG, M. Fundamentals of Machine Operation. Moline-IL : John Deere Service Training, 1981. p. 12.

GRANDJEAN, Etienne. Manual de Ergonomia, 4. ed., Porto Alegre - RS : ed. Artes Médicas Sul, 1998, pp. 200-213.

GRAY, R. B. The Agricultural Tractor: 1855-1950. [s.1.]. American Society of Agricultural Engineers, 1975, p. 12.

HARTOG, J.P. Den, Vibrações nos sistemas mecânicos ed. Edgard Blücher, 1972, p.1

HERRMANN, Klaus, Traktoren in Deutschland 1907 bis heute, 46. ed., [s.l:s.n.], 1993, 208 p.

IIDA, Itiro. Ergonomia: Projeto e Execução, 4. ed., São Paulo-SP : ed. Edgard Blucher , 1997, $465 \mathrm{p}$.

ISO -INTERNATIONAL ORGANIZATION OF STANDARDIZATION. Norma ISO 5721/1981: Agricultural tractors - Operator's field of vision.

MARQUEZ, Luis. Solo Tractor 90, In Ergonomia e Segurança no Projeto e Utilização de Máquinas Agrícolas, p. 177-194, Santa Maria - RS, 1997.

MENEZES, João F., MAZIERO, José V., YAMASHITA, Rosa Y. et al. Avaliação de Características de Visibilidade Apresentadas por um Grupo de Tratores de Rodas, 17 p., Instituto Agronômico, Campinas - SP, junho de 1985.

NETTO, João Cândido F. 'Tração animal complementa a mecanização'. PiracicabaSp: Coletânea de artigos sobre mecanização agrícola e máquinas agrícolas, 1 v., p. 8-10, 1985.

SCHLOSSER, J. F.; SOUZA F , E.G. de; WILLES, J. A.; MACHADO,O. D. at all. Alteração do nível de ruído pela adição de cabinas em tratores agrícolas. In: VI CONGRESO ARGENTINO DE INGENIERÍA RURAL, 2000, Buenos Aires - República Argentina. Anais. 6 p.

TOLAINO, Osiris. "Em 1880 já se pensava em trator". Piracicaba-SP. Coletânea de artigos sobre mecanização agrícola e máquinas agrícolas, 1 v., pp. 81-82, 1985. 
Artigo recebido em $\mathrm{xx} / \mathrm{xx} / \mathrm{xx}$ e aceito para publicação em $\mathrm{xx} / \mathrm{xx} / \mathrm{xx}$ 